\title{
Study on Ultrasound-assisted Extraction of Flavonoids from Navel Orange Peel
}

\author{
Xiaokang $\mathrm{Li}^{1} \mathrm{a}^{*}$, Yangqin Jiang ${ }^{1}$, Kejun Wang ${ }^{1}$, Jiong Chun ${ }^{2}$, Balian Zhong ${ }^{2} \mathrm{~b}^{*}$ \\ ${ }^{1}$ Key Laboratory of Organo-pharmaceutical Chemistry, Gannan Normal University, Ganzhou, \\ Jiangxi, China. \\ ${ }^{2}$ National Navel Orange Engineering Research Center, Gannan Normal University, Ganzhou, \\ Jiangxi, China. \\ a*email: xkangli@126.com \\ b*email: bal.zh@163.com
}

Key words: flavonoids; navel orange peel; ultrasonic

Abstract: A new extraction of flavonoids from navel orange peel by optimization of ultrasound-assisted were studied, The effects of ethanol concentration, liquid/solid ratio, extraction temperature, ultrasonic time, and extraction time were investigated. The results showed that: the extraction yield of flavonoids can be rased to $3.16 \%$ in optimum conditions. Meanwhile, orthogonal design and variance analysis were used to optimize the experiments.I

\section{Introduction}

With the rapid development of navel orange juice processing industry, there are a lot of navel orange peels produced that have not been fully utilized each year. Orange peel is rich in flavonoids, essential oils and other ingredients . Many studies have shown that flavonoids have lipid-lowering, anti-cancer, anti-oxidation, which are widely used in medicine, food and other fields with a very wide range of application value. Ultrasound is an effective method for the extraction of natural active ingredients from plants. The principle of this method is the use of ultrasonic cavitation to accelerate the dissolution of the active ingredients from the plant. Compared with traditional methods, ultrasonic method has many advantages such as short extraction time, high efficiency, does not destroy the structure of component, etc. In this work, the extraction of flavonoids from navel orange peel by optimize of ultrasound-assisted were studied.

\section{Results and discussion}

\section{The effect of ethanol concentration on the yield of flavonoids}

The effect of ethanol concentration on the yield of flavonoids was carried out under different ethanol concentrations $(40 \%, 50 \%, 60 \%, 70 \%$, and $80 \%$, respectively), whereas other extraction parameters were constant (liquid-solid ratio $20 \mathrm{~mL} / \mathrm{g}$, ultrasonic time $40 \mathrm{~min}$, extraction temperature $70{ }^{\circ} \mathrm{C}$, extraction time $90 \mathrm{~min}$ ). The result was shown in Fig.1. As can be seen from Fig.1, when the ethanol concentration was from $40 \%$ to $60 \%$, the yield of flavonoids increased with increasing ethanol concentration, but when the ethanol concentration exceeded $60 \%$, its yield increased as the concentration of ethanol reduced. The main reason may be polarity is different with different ethanol concentration, under the influence of ultrasound, when the ethanol concentration was $60 \%$, it has the similar polarity as flavonoids to make it reach the maximum solubility. When ethanol concentration is low, the extraction of flavonoids was incomplete. Too high ethanol concentration will lead to difficulty in separation and purification. So $50 \%$ to $70 \%$ ethanol concentrations were chosen as level factors, and the proposed concentration was $60 \%$. 


\section{Effect of liquid/solid ratio on the extraction yield of flavonoids}

The effect of liquid/solid ratio on the yield of flavonoids was carried out under different liquid-to-solid ratios $(10,15,20,25$, and $30 \mathrm{~mL} / \mathrm{g}$, respectively), whereas other extraction parameters were constant (ethanol concentration $60 \%$, ultrasonic time $40 \mathrm{~min}$, extraction temperature $70{ }^{\circ} \mathrm{C}$, extraction time $90 \mathrm{~min}$ ). The result was shown in Fig.2. As can be seen from Fig.2, with the increase of the liquid-to-solid ratio, the yield of flavonoids increased rapidly; when the liquid ratio greater than $20 \mathrm{~mL} / \mathrm{g}$, the yield gradually stabilized. When liquid ratio is too small, it is difficult to ensure that all flavonoids were transferred from the raw materials to the liquid phase. When liquid ratio is too large, it will consume large quantities of alcohol and take longer time to concentrate the extract. Taken together, $20 \sim 25 \mathrm{~mL} / \mathrm{g}$ of liquid/solid ratio was appropriate.

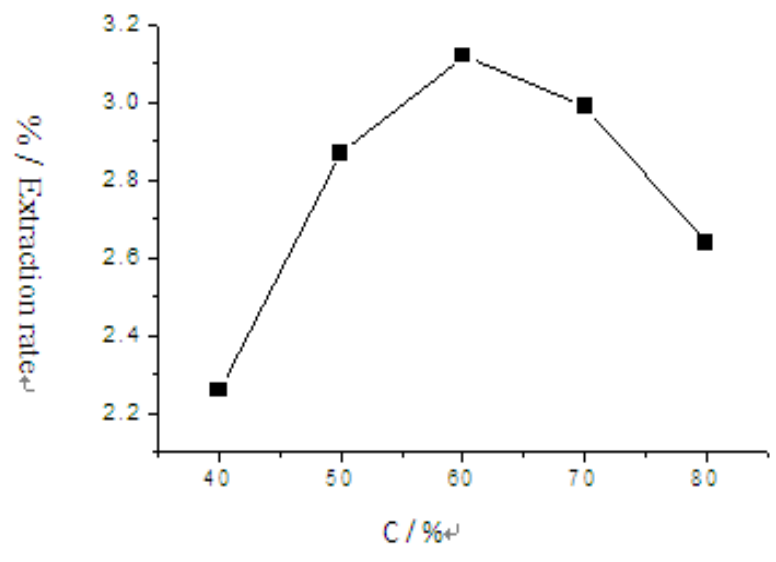

Fig.1 The effect of ethanol on extraction rate

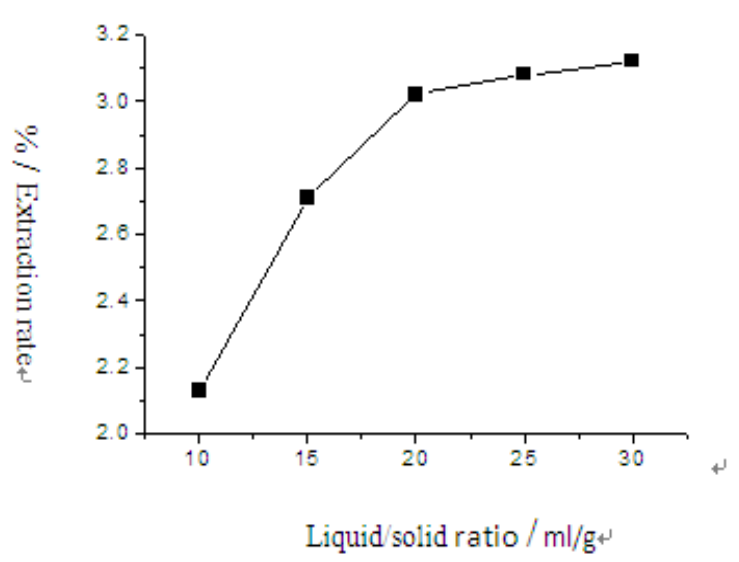

Fig. 2 The effect of liquid/solid ratio on extraction rate

\section{Ultrasonic time on the yield of flavonoids}

The effect of ultrasonic time on the yield of flavonoids was carried out at different ultrasonic time (30, 45, 50, 60, and $70 \mathrm{~min}$, respectively), whereas other extraction parameters were constant (ethanol concentration $60 \%$, liquid-to-solid ratio $20 \mathrm{~mL} / \mathrm{g}$, extraction temperature $70{ }^{\circ} \mathrm{C}$, extraction time 90 min). The result was shown in Fig.3. As can be seen from Fig.3, with the extension of ultrasonic time, the yield of flavonoids from navel orange peel increased gradually, which reached maximum at 60 min. However, when the ultrasonic time was longer than the $60 \mathrm{~min}$, the yield decreased with the extension of the ultrasonic time. The reason may be with prolonged ultrasound, some of flavonoids inside navel orange peel may be destroyed. Therefore, ultrasonic time was scheduled for 60 min.

\section{Effect of extraction temperature on the yield of flavonoids}

The effect of extraction temperature on the yield of flavonoids was carried out at different temperatures $\left(40,50,60,70\right.$, and $80{ }^{\circ} \mathrm{C}$, respectively), whereas other extraction parameters were constant (ethanol concentration $60 \%$, liquid-to-solid ratio $20 \mathrm{~mL} / \mathrm{g}$, ultrasonic time $60 \mathrm{~min}$, and extraction time $90 \mathrm{~min}$ ). The result was shown in Fig.4. As can be seen from Fig.4, the yield of flavonoids increased with increasing temperature. When the extraction temperature is $70{ }^{\circ} \mathrm{C}$, the maximum yield of flavonoids was reached. But the yield was worse when extraction temperature was higher than $70{ }^{\circ} \mathrm{C}$, which might due to thermal stability of flavonoids at high temperature . So $70{ }^{\circ} \mathrm{C}$ was chosen as extraction temperature. 


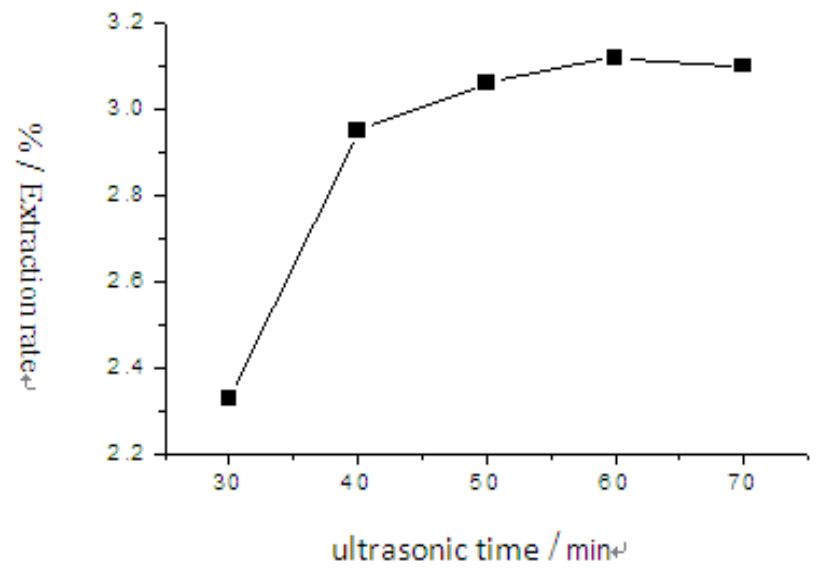

Fig.3 The effect of ultrasonic time on extraction rate

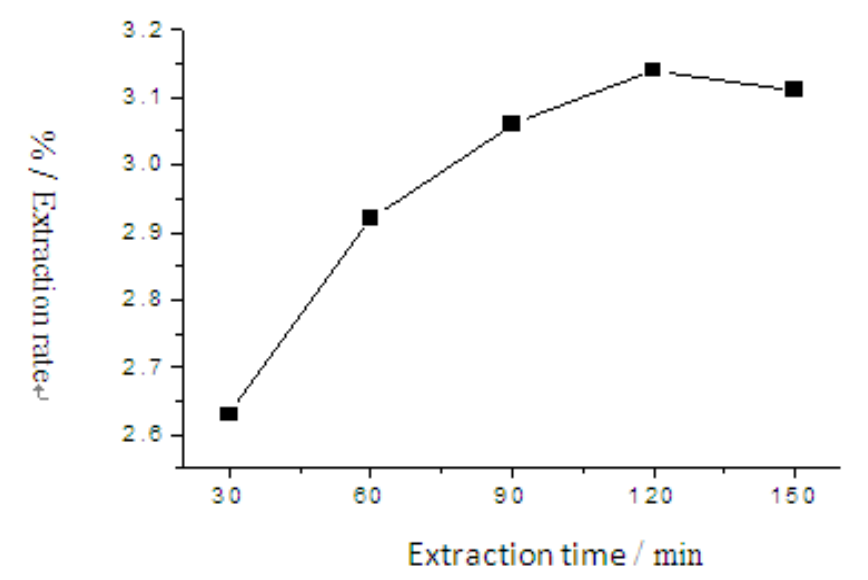

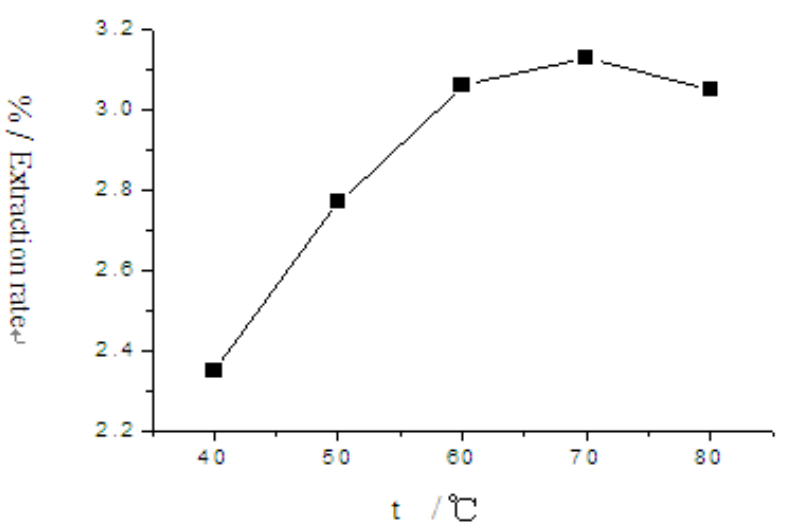

Fig.4 The effect of temperature on extraction rate

Fig.5 The effect of extraction time on extraction rate

\section{Effect of extraction time on the yield of flavonoids}

The effect of extraction time on the yield of flavonoids was carried out at different time $(30,60,90$, 120 , and $150 \mathrm{~min}$, respectively), whereas other extraction parameters were constant (ethanol concentration $60 \%$, liquid-to-solid ratio $20 \mathrm{~mL} / \mathrm{g}$, and ultrasonic time $60 \mathrm{~min}$ ). The result was shown in Fig.5. As can be seen from Fig.5, with the extension of the extraction time, the yield of flavonoids increased gradually. When the extraction time was about $120 \mathrm{~min}$, the maximum yield was obtained. However, when extracting time was more than $120 \mathrm{~min}$, the yield declined. In order to reduce energy consumption the extraction time was set to $120 \mathrm{~min}$.

2.6 The experiments of optimum extraction process

As shown in single factor experiments, orthogonal design and variance analysis were used to optimize the extraction of flavonoids from navel orange peel by optimize of ultrasound-assisted. The optimal extraction conditions were: ethanol concentration $60 \%$, liquid/solid ratio $25 \mathrm{~mL} / \mathrm{g}$, extraction temperature $60{ }^{\circ} \mathrm{C}$, ultrasonic time $60 \mathrm{~min}$, and extraction time $120 \mathrm{~min}$. The validation test results under optimum conditions were shown in Table 1. From Table 1, the results under optimum conditions were consistent.

Table 1 Results of testing experiments

\begin{tabular}{c|cccccc}
\hline $\begin{array}{c}\text { Experiment } \\
\text { number }\end{array}$ & 1 & 2 & 3 & 4 & 5 & Mean value \\
\hline $\begin{array}{c}\text { Extraction yield } \\
\text { of flavonoids \% }\end{array}$ & 3.14 & 3.16 & 3.15 & 3.18 & 3.16 & 3.16 \\
\hline
\end{tabular}




\section{Conclusions}

Based on single factor experiments, orthogonal design and variance analysis were used to optimize the extraction of flavonoids from navel orange peel by optimize of ultrasound-assisted, it shown that the best optimization parameters were: ethanol concentration of $60 \%$, liquid/solid ratio $25 \mathrm{~mL} / \mathrm{g}$, extraction temperature $60{ }^{\circ} \mathrm{C}$, ultrasonic time $60 \mathrm{~min}$, and extraction time $120 \mathrm{~min}$. Under this condition, the extraction yield of flavonoids from orange peel was $3.16 \%$. This process was adapted to flavonoids extraction from orange peel with good consistence.

\section{Acknowledgements}

This work was supported by Science and Technology Project Foundation of Jiangxi Province, China (20132BBG70042).

\section{References}

[1]YI Zhibiao, Yu Yan, Liang Yizeng, In vitro antioxidant and antimicrobial activities of the extract of Pericarpium Citri Reticulatae of a new Citrus cultivar and its main flavonoids[J]. LWT-Food Science and technology, 2008, 41(4): 597-603.

[2] Tsuyoshi Inoue, Shuntaro Tsubaki.Jun-ichi Azuma,Isolation of hesperidin from peels of thinned Citrus unshiu fruitsby microwave-assisted extraction[J]. Food Chemistry, 123 (2010) 542-547.

[3] Ortuo A, Bidez A, Gmez P, et al. Citrus paradisi and Citrus sinensis flavonoids: Their influence in the defence mechanism against Penicillium digitatum[J]. Food Chemistry, 2006, 98(2): 351-358. nstitute of Metals, 2005 , 69 (2):198-201.

[4] Iwase Y, Takeumra Y, Juichi M, et al. Inhibitory effect of flavonoids from Citrus plants on Epstein-Barr virus activation and two-stage carcinogenesis of skin tumors[J]. Cancer Letters, 2000, 154(1): 101-105.

[5] Ma, Y., Ye, X., Fang, Z., Chen, J., Xu, G., Liu, D. Phenolic compounds and antioxidant activity of extracts from ultrasonic treatment of Satsuma Mandarin peels[J]. Journal of Agricultural and Food Chemistry,2008.56,5682-5690.

[6] Tsubaki, S., Iida, H., Sakamoto, M.,Azuma, J. Microwave heating of tea residue yields polysaccharides, polyphenols, and plant biopolyester[J].Journal of Agricultural and Food Chemistry,2008. 56, 11293-11299. 